\title{
Ho Chi Minh's thought About Self-study and Application in Vietnam Today
}

\author{
Dr. Nguyen Minh Tri ${ }^{(1 *)}$ and Dr. Nguyen Anh Thuong ${ }^{(2)}$
}

(1)Ho Chi Minh City University of Technology (HUTECH), Ho Chi Minh City, Vietnam.

(2) University of Social Sciences and Humanities - Viet Nam National University Ho Chi Minh City (VNUHCM -USSH), Vietnam.

*Corresponding Author's: nm.tri@hutech.edu.vn

\begin{abstract}
Self-study and lifelong learning are important points in Ho Chi Minh Thought on education. Being himself an example of lifelong learning, Ho Chi Minh left many valuable lessons and instructions, including fundamental points, for us to study and follow. Given the requirements of the education renovation to promote the proactiveness and creativity of learners, self-study plays a crucial role. However, current activities of self-study and self-research by Vietnamese pupils and students have not been given adequate attention to, and the results have been very modest, yet to meet the requirements of the reality. Therefore, improving the self-study capacity in education and training following Ho Chi Minh self-study example bears an extremely important meaning nowadays.
\end{abstract}

Keywords: Ho Chi Minh's thought, self-study, education, thought value, Vietnam today

\section{Introduction}

Ho Chi Minh's thought is a comprehensive and profound system of views on the fundamental issues of the Vietnamese revolution, from the people's democratic revolution to the socialist revolution; is the result of the creative application and development of Marxism-Leninism in the specific conditions of our country and at the same time the crystallization of the national quintessence and age intelligence to liberate the nation, liberate the period granting and liberating people (Communist Party of Vietnam, 1991).

Depending on the different bases and senses, his thoughts can be delineated according to any specific content. In general, Ho Chi Minh's thought can include parts such as philosophical thought, political thought, economic thought, humanistic moral thought, cultural thought, military thought, diplomatic thought, etc. In which his thought about self-study is one of the very important content. During his life, Ho Chi Minh special attention to the educational development of the country. Who have very valuable instructions on educational objectives, tasks, content and methods... in order to develop a comprehensive education. Those instructions still have the guiding value, pave the way for the fundamental and comprehensive renovation of education and training in our country today.

In the condition of information explosion, without self-study, self research and self-training, it is impossible to keep up with the advances of modern science. In order to adapt to life as well as 
meet the needs of society, learners must actively self-study, continue learning and lifelong learning.

This article analyzes Ho Chi Minh's thoughts on self-study and application in Vietnam.

Two research questions are revealed as following:

Question 1: What was the content of Ho Chi Minh's thoughts on self-study?

Question 2: How to apply Ho Chi Minh's thought on self-study in Vietnam today?

\section{Research Methods}

\section{Method and Data}

The paper's approach is based on the worldview and the methodology of Marxist philosophy, and at the same time uses specific research methods such as analysis and synthesis, logic and history, inductive and interpretation, abstraction, generalization, comparison, comparison and literary methods for research and presentation.

\section{Research results}

\section{Ho Chi Minh's views on self-study}

During his life, Ho Chi Minh said: "An ignorant people is a weak people" (Minh, 2011, vol 5, p.7), so fostering the next generation of revolution is very important and necessary. According to him, education and training played a great role in the revolution in building and perfecting a new human personality for a comprehensive development. Therefore, education must be done in all areas of life, the school is associated with the family and society, learning goes hand in hand with practice and production labor. In order to become talented, virtuous and useful citizens for the society, in addition to the education of the school, family and society, it is required that each student must educate himself, self-study, and self-training to complete yourself. Ho Chi Minh said that self-education and self-study are important because the educational process is after all to aimed at arousing and promoting learners' self-education. This process cannot achieve results if learners do not consciously make efforts to study, acquire knowledge, turn human knowledge into personal knowledge. Therefore, he reminded Party members to study and work in revolutionary activities for life, they still have to learn while living, and still have to do revolutionary activities. Learning is not only a privilege of one person but the duty and benefit of all people, of the whole society.

Ho Chi Minh reminded the education sector as well as each learner to improve and guide selfstudy. He said: "It is not like studying in the old-fashioned schools, if you don't have a teacher, you will learn, you will joke if you don't come. Must know automatically learning" (Minh, 2011, vol 6, p.360). He said that our new education aims to turn the training process into a self-training process, to gain mastery of scientific knowledge and understanding as well as the ability to practice in all aspects of life. Since then, Ho Chi Minh has provided correct, practical and effective instructions for learners to conduct self-study. The core of self-study is self-awareness of learners. In the process of self-study, the most important issue is self-examination and assessment of self-study results. Because, if tested, incorrectly assessed, it will lead to delusions about capacity or inferiority, not believing in self-study and self-study ability of self-study subjects. Accurate self-assessment will help learners clearly see their own strengths and weaknesses, clearly see the content that needs to be added, and then continue self-study activities. Through self-study capacity of learners is increasingly developed and perfected as the process of resolving internal conflicts of learners. Self-assessment can only become a driving force for self- 
study to develop when Ho Chi Minh self assessment (the subject of self-study) have an objective and honest attitude towards the results they have achieved.

According to Ho Chi Minh, self-study is a continuous flow, constantly developing, learners must not let it interrupt, without interruption, no matter how busy work life is. Later, despite being busy with hundreds of thousands of jobs at the position of the head of our government, he often taught himself, fostered and supplemented his own knowledge, was a shining example of knowledge receptive and creation.

It can be said that, Ho Chi Minh 30-year journey through many countries around the world to find a way to save the country and learn how to regain national independence is also the continuation of the path of self-study and self-study that he did. Beginning at a young age, with an extraordinary will and energy. In those days, there is always a close connection between the working process and his self-study process. Although the work is very hard, life is difficult and lacks, but he always takes advantage of studying everywhere, every time possible, in all forms and means available. While on board admiral Latusơ Torêvin, he usually read or write until eleven o'clock or midnight. When in Saint Adret, while temporarily at a shipowner's house, he learned French with his maid. To learn new words, he wrote on a piece of paper on conspicuous places, sometimes writing on his arm so that while traveling or working, he could study. At night, when he did not sleep, he used his hand to write difficult words on the blanket to remember and so every day he learned a few new words. And so, with the spirit of eager to learn constantly, Ho Chi Minh traveled to many countries around the world, working for a living, studying and revolutionary activities.

During his time in England, he worked in many different jobs to earn money for his education. During the war, he spent time studying world history, studying English and thinking about the future of colonial peoples. Thanks to the right and strong motivation for studying, he has found many intelligent and creative ways to learn. Study in books, in people around, study at the library, in the park, study on the road... In the resumes of delegates attending the 7th Communist International Congress in 1935, in the education level, he write: self-study. And write the foreign languages known as English, French, Chinese, Italian, German, and Russian. In 1928-1929, while working in Siam, he also learned Siam with determination and perseverance, learning only 10 words a day, while others eagerly learned at first but later quit. Later, when he returned home to participate in revolutionary activities and lived with ethnic minorities, Ho Chi Minh learned the Tay and Nung languages again. Even when taking on the position of President, Ho Chi Minh was still diligently studying, practicing, and studying the people. People who quickly penetrate into reality, grasp knowledge about fields and objects before making contact and exchange, conquers everyone. He himself also affirmed that all his knowledge about history, culture, politics, philosophy, military, economics... and his creativity in revolutionary activities was selfstudy have been.

It can be said that self-study in Ho Chi Minh is persistent and creative self-study, such as how learners write newspapers. Although he does know French because he was learned while studying at Hue National School but did not have enough capital to write books and newspapers, he started studying journalism. Often visiting the People's Court, Ho Chi Minh got acquainted with the editor of the Boat Worker's Life newspaper. It was very difficult to write news at first, news about Vietnam he was not lacking anything, but the most lacking was French literature. He 
made two copies, sent one copy to the newspaper, kept one copy (there was no photocopy at that time) to compare with the printed newspapers, and corrected the false writings, patiently doing so. That way brought Ho Chi Minh into the newspaper industry, very naturally, and became an excellent writer praised by many professional journalists.

In addition to studying journalism, Ho Chi Minh accumulated linguistic and literary capital. $\mathrm{He}$ has enlisted anytime, anywhere to read books of famous writers, poets and playwrights in the world. Ho Chi Minh taught himself comprehensively. Learn foreign languages, learn to write articles, study Marxism-Leninism, research and selectively absorb the quintessence of human culture, especially Eastern culture and Western culture. People know and use more than ten languages fluently through self-study, not through a formal training school. Learners from real life in books, colleagues, friends, people. Learners from real life in imperial countries, colonial countries, in revolutionary movements in the world.

Self-study in Ho Chi Minh is combined with real life and revolution, taking labor as the basis for self-study. On August 17, 1962, talking to teachers and students at Hoa Binh Socialist School of Labor, Ho Chi Minh, told: "Before when I was young, i worked in France, working and studying at the same time, but at that time labor was slave labor for the empire. You have to do that to make a living by yourself, but you still spend time studying, working day, night studying, but you can't go to school" (Minh, 2011, vol 13, p.437). While living in France, he worked as a photographer and an exaggerator of photos, taught by old man Phan Chu Trinh. Usually he only works half a day in the morning to make money, while in the afternoon he goes to the library or attend talks. Evening is the time when he goes to the rallies. During most of these rallies, he expressed his opinion and was very skillful in stepping the discussion to colonial matters. People get acquainted with politicians, writers to improve their political and literary level. In the process, Ho Chi Minh never forgot to learn to enrich his theoretical knowledge and practical experience. Regardless of the circumstances, at any time, Ho Chi Minh persisted in studying. "Learning is something that must continue for life," he said. Life must be associated with theory with practical work. No one can claim that they already know enough, know it all. The world is changing day by day, our people are progressing more and more, so we must continue to learn and practice to make progress with the people" (Minh, 2011, vol 10, p.377). He said that if we try, all difficulties can be overcome. During a conversation with officials and party members, who have been active for a long time, he confided that he was 71 years old this year, but every day he studied, work kept going, if he did not study, he could not keep up, his work would deceive him back to the back. Not just calling, motivating, encouraging the spirit of enthusiasm, and perseverance in learning that Ho Chi Minh himself is a vivid testament to that spirit. The person who has spent a life of hardship, difficulty, and need, while working to earn money while studying by himself in a foreign country, and who still does not stop studying at an old age, is the leader of the nation. Overcoming these difficulties is a passionate inquisitive spirit of the revolutionary for purpose, noble ideals and the achievements of knowledge both in theory and practice to serve the cause of the struggle. National Liberation.

Uncle Ho's life is a process of learning and revolutionary activities; learning to act in a revolutionary way, to achieve your goals, your ideals; through revolutionary activities, constantly learning, perfecting their own knowledge and personality. He has left a fine example of self-study and lifelong learning for us to follow. 


\section{Applying Ho Chi Minh's ideology on self-study in Vietnam today}

Self-study and self-training of learners have been deeply concerned by the Party and State from a very early age. Central Resolution V term 8 states: "Focusing on improving the quality of teaching and learning, creating self-learning capacity, self-creativity of students, ensuring all conditions and time for self-study for students, to strongly develop the movement of regular and widespread self-study and self-training among the entire population" (Communist Party of Vietnam, 2013). After 35 years of innovation, the education sector has also achieved many achievements in both quality and quality. Ho Chi Minh example of self-study has been pervasive throughout the education sector. In that spirit, the education sector also actively renewed teaching and learning methods in the spirit of giving initiative and creativity to learners. Pupils and students had initial awareness of Ho Chi Minh's thought, self-study example. Realizing the need to apply that thought and example in improving the quality of self-study. However, at present, there are still many shortcomings in teaching and learning. In class sessions, very few students express their opinions, argue and discuss with their teachers' friends. In addition, students do not actively participate in the lesson, do not know how to choose basic and meaningful knowledge to take notes, and the way to take notes is rampant and general, so when studying, it will be difficult to understand. difficult to memorize, which in turn leads to a decrease in interest in learning. Ho Chi Minh said that students should not be trained and educated as passive and mechanical people, but need to deepen their thinking and emphasize self-learning ability, learning must take self-study as the core and must have self-study instruction. This is an active teaching method of era - democracy and humanity because it focuses on learners to ensure the interests of learning and development for learners.

There are still many limitations in teaching work. A part of teachers do not have the correct awareness of active teaching methods, claiming that this teaching method is not much different from the old method, so they keep teaching traditional methods: reading - writing, The teacher is central, as long as it is effective, students understand the test, pass the test, and return high scores. Such simple perception and thinking not only do not create opportunities to approach new methods, limit the qualifications and professional capacities of lecturers, but also affect, Negative impact on other teachers. Those who want to approach and renew their teaching methods to attract and attract students. In that way, the limitations in awareness of this teaching method have been and are inhibiting the progress, limiting the quality of education and training of the schools. Thoroughly grasping Ho Chi Minh's spirit of self-study, the education sector needs to renovate both current teaching and learning methods.

Firstly, to raise awareness of self-study for students, students, lecturers and administrators of colleges and universities. Schools should have training for teachers so that they can incorporate self-study skills in the field into their specialized subject content. To provide lecturers with modern, learner-centered teaching methods, promoting to the highest level the initiative and enthusiasm of learners. In addition, there should be measures to motivate lecturers, to design to add a certain proportion of the teaching time to implementing new learning methods for students. And so, the evaluation of faculty should have points for investing time and applying active teaching methods and teaching appropriate learning methods for students according to the required characteristics of the subject learning and students' ability to absorb. To do that, it is essential to raise awareness of self-study for students, faculty and administrators. This is the 
basic way to form a sense of self-study for students, lecturers and administrators because the perception process is the process of arriving at the objective truth. Effectiveness and raising awareness of self-study for students, faculty and administrators at all levels will create a topdown consistency about the importance of self-study.

Second, innovate teaching methods and test and evaluate in order to improve and guide the selfstudy and self-study of students and students. Teachers must be able to stimulate demand and stimulate learning for learners. This should be done continuously in the course of class, requiring teachers to know how to ask problems, solve problems scientifically and help learners easy to absorb lessons, actively participate in lessons, and want to learn by themselves. I learn, discover knowledge. It is necessary to increase guidance and help learners to develop a scientific selfstudy plan that is reasonable and suitable for their conditions to reach the goal in the most effective way. For the subjects that need practical connection, teachers should give more situations, many practical examples... thereby forming for students how to work seriously, positively and the will to strive for improvement. to achieve high results in school. Modern lectures tend to use more and more information technology means to increase their attractiveness and efficiency. Today, in schools are equipped with facilities for teachers to choose from to serve lectures such as projectors, audio tapes, video tapes... Teachers have to make use of those means to do their work. tools to innovate teaching methods that stimulate students' interest in learning. Third, increase self-study skills education for pupils and students. Need to have a reasonable study plan, students must know how to build their own learning goals and plans. In particular, learners must formulate their own appropriate measures to implement the proposed plan. For self-study to be effective, learners must determine effective reading time, should read before class, learn new lessons by themselves, find out places that are still not understood and prepare questions to ask teachers when possible. Having the spirit of studying regularly and especially knowing to determine the focus and focus of the lesson.

To improve students' self-study capacity, students need to synchronously implement a series of solutions from students themselves to lecturers, schools, administrators... in which learners themselves play the role. decisive game. Today's Vietnamese students are striving, constantly learning to improve their knowledge and professional skills, ethics, to meet the increasing demands of society. That is also the realization of the application of Ho Chi Minh thought and self-study example in the current period.

\section{Conclusion}

The development of our country in the current period is creating conditions for the young generation to have opportunities to go to school to study, improve knowledge and integrate into the world. However, no matter how good the school is, it cannot meet all the learning needs of learners as well as the increasing demands of social life. Faced with the requirement of educational innovation in order to promote learners' initiative and creativity, self-study has a very important role. Immediately with Ho Chi Minh perspective and example of self-study, learners must constantly study by themselves, try to gain knowledge, and at the same time teachers also have practical measures to guide, test and evaluate to forming and enhancing selfstudy capacity for students to master knowledge. Therefore, fostering self-study capacity for students and students plays an important role in schools. Only by self-study and self-enrichment 
with many different ways and ways can learners make up for the shortcomings of scientific knowledge and social life; from there, gain confidence in life and work by its comprehensive capacity to meet the increasing requirements of the country's renewal cause.

\section{Acknowledgement}

We would like to express the anonymous research participants for their willingness to have taken part in this study. Additionally, our sincere gratitude should go to other relevant parties who have given comments and supported us during our study. Without their unconditional help and support, we would have never been able to finish this study.

\section{Conflit of interest}

The authors declare that they have no competing interests.

\section{References}

1. Communist Party of Vietnam. (1991). Document of the 7th National Party Congress. Hanoi: The Truth.

2. Communist Party of Vietnam. (2013). Resolution of the Central Conference 8 Session XI Transforming basically, comprehensively education and training. Hanoi.

3. Communist Party of Vietnam. (2016). Document of the 12 th National Congress of the Party. Hanoi: National Politics.

4. Communist Party of Vietnam. (2021). Document of the 13 th National Congress of the Party. Hanoi: National Politics.

5. Dung, N. T. K. D., \& Nhuan, T. T. N. (2013). Uncle Ho with education and training. Hanoi: Social labors.

6. Giap, V. N. (1994). Historical journeys. Hanoi: National Politics.

7. Giap, V. N. (2015). Research, study, and follow Ho Chi Minh's thoughts. Hanoi: The People's Police.

8. Nien, N. D. (2008). Ho Chi Minh's diplomatic memorial. Hanoi: National Politics.

9. Minh, H. C. (2011). Complete set, Volume 3. Hanoi: National Politics.

10. Minh, H. C. (2011). Complete set, Volume 4. Hanoi: National Politics.

11. Minh, H. C. (2011). Complete set, Volume 6. Hanoi: National Politics.

12. Minh, H. C. (2011). Complete set, Volume 10. Hanoi: National Politics.

13. Minh, H. C. (2011). Complete set, Volume 13. Hanoi: National Politics.

14. Moi, L. M. (2000). University teaching theory. Hanoi: Education.

15. Tuyen, T. D. (2001). Teaching self-study for students in professional high schools and colleges and universities. Hanoi: Education.

16. Trung, N. X. (2019). Applying Ho Chi Minh's ideology to research, creative theoretical development in Vietnam in the current period. Communist Journal. Retrieved from https://www.tapchicongsan.org.vn 